Document downloaded from:

http://hdl.handle.net/10251/44609

This paper must be cited as:

Vercher Sanchis, JM.; Gil Benso, E.; Mas Tomas, MDLA.; Cubel Arjona, FJ. (2014). Analysis of the residual safety level in $\mathrm{R} / \mathrm{C}$ slabs with severe joist corrosion. Journal of Performance of Constructed Facilities. 1-14. doi:10.1061/(ASCE)CF.1943-5509.0000608.

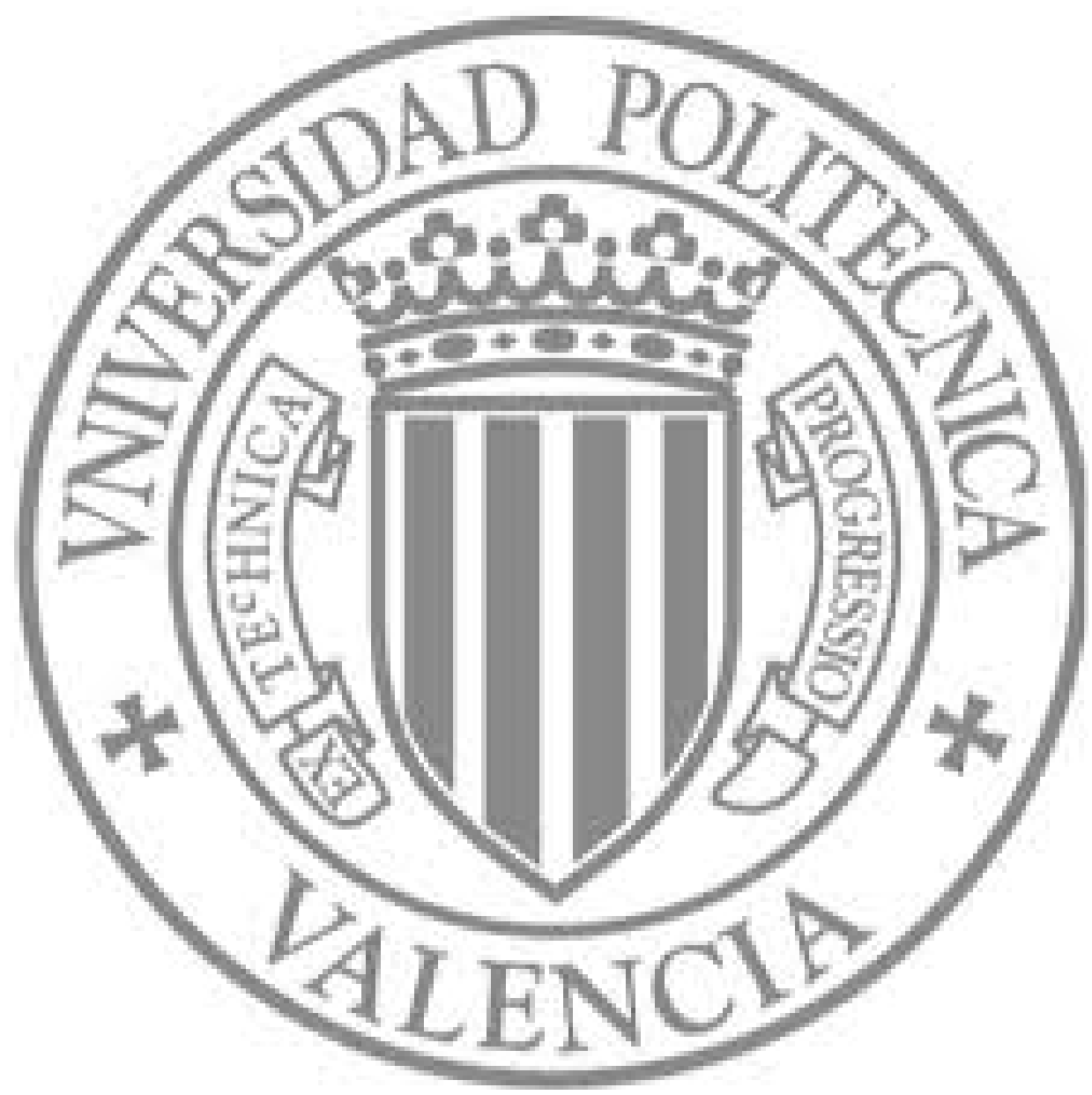

The final publication is available at

http://dx.doi.org/10.1061/(ASCE)CF.1943-5509.0000608

Copyright American Society of Civil Engineers 


\title{
Analysis of the residual safety level in R/C slabs with severe joist corrosion
} Jose Vercher ${ }^{1}$, Enrique Gil², Angeles Mas ${ }^{3}$, Francisco Cubel ${ }^{4}$

\begin{abstract}
An analysis until the failure on a series of one-way slabs with severe corrosion at the lower reinforcement of the $\mathrm{R} / \mathrm{C}$ joists is presented.

Different positions in the slab and number of damaged joists have been studied, obtaining the residual safety assessment in cases of slabs damaged by flexural failure mechanisms.

Since the boundary conditions have proved decisive for obtaining the behavior, the damaged slab has been evaluated as part of the entire building, as precisely as possible, taking into account the different phases of the construction process and deterioration in time, and the complex behavior of concrete, steel and masonry. The results of the proposed methodology are consistent with the pathology of the observed cases.

As a result of this study the authors propose practical recommendations to help in making decisions about the magnitude of the intervention, always necessary in this type of pathology.
\end{abstract}

\section{Subject Headings}

Structural Safety; Concrete Slabs; Reinforced Concrete; Damage; Joists; Corrosion; Control Surveys; Diagnosis

\footnotetext{
${ }^{1}$ Assistant Professor, Department of Architectural Constructions, Polytechnic University of Valencia, Camino de Vera s/n, Valencia 46022, Spain, jvercher@csa.upv.es

${ }^{2}$ Titular Professor, Department of Continuum Media Mechanics and Theory of Structures, Polytechnic University of Valencia, Camino de Vera s/n, Valencia 46022, Spain, egil@mes.upv.es
} 


\begin{abstract}
${ }^{3}$ Titular Professor, Department of Architectural Constructions, Polytechnic University of Valencia,
Camino de Vera s/n, Valencia 46022, Spain, amas@csa.upv.es

${ }^{4}$ Assistant Professor, Department of Architectural Constructions, Polytechnic University of Valencia, Camino de Vera s/n, Valencia 46022, Spain, fcubel@csa.upv.es
\end{abstract}

\title{
Introduction
}

The results of technical evaluations show that damage due to reinforcement corrosion is among the first three causes of deterioration in concrete structures (Trocónis 2006). Specifically, Spanish Concrete Group -GEHO- analyzed 844 cases with different pathologies in Spain, with reinforcement corrosion taking important place as the most frequently occurring pathology among the problems detected (GEHO 1992). Excessive deformation ranks first with $22 \%$ of cases, the reinforcement corrosion represents $15 \%$, and cracking is the cause of deterioration in $2 \%$ of cases.

Unfortunately, the use of aluminous cement in Spain has forced to assess and develop the rehabilitation project of thousands of dwellings with severe corrosion of the reinforcement. Prefabricated joists were widely used because of the speed of aluminous cement setting during the years 1950 to 1970 . The posterior conversion of this type of cement and the presence of moisture accelerates the corrosion of reinforcement in the prefabricated joists, both with prestressed reinforcement as nonprestressed reinforcement, the latter being less used.

The authors have performed costly experimental tests in some damaged slabs. Some damaged joists are taken from slab, removing the concrete compression layer, the mesh and the concrete blocks. And subsequently made pure bending test of 
these nerves. With the performing of the test on the isolated joist, which will have eliminated the other building elements, it does not reach a sufficient safety, since the corrosion of the reinforcement prevents the bond with the concrete. This does not correspond with the low degree of deformation and cracking observed in some cases the building, where the joist is part of the whole slab.

Due to the mismatch between the results observed in the building and those extracted from the experimental work is necessary to contemplate the real boundary conditions in a simulation. Therefore, the simulation was made of an intermediate slab restricted by the boundary conditions as real as possible.

The evaluation of the reliability is made on three-dimensional models. By analyzing the structures in space rather than using lineal models, other ways of working can be observed: the arch effect (Coronelli and Gambarova 2004); the membrane effect (Foster et al 2004); and the formation of struts and ties, as well as the transmission of loads in space. All this gives an estimation according to the observed pathology. When structural elements are simplified through their neutral lines, the minimum work under which a supporting structure actually behaves does not appear. The present work is realized by spatial models, due to when pathology appears, these other ways of working are very important to assess the remaining safety. In this investigation, simulations have been made with different cases of corroded reinforcement, and a high proportion between the ultimate load and the service load is obtained when corrosion affects up to three neighboring joists. This observation also corresponds with the surveying experience of the research team.

The proposed method can estimate the remaining safety in these cases and help in making decisions about the intervention to be performed. The rehabilitation project can range from a light intervention to the evacuation of the building. 


\section{Significant influence of reinforcement corrosion}

The severity of corrosion with loss of steel section depends on the percentage of reinforcement section lost, whether or not the linkage between concrete and steel is lost, and whether the concrete is reinforced or pre-stressed. Corrosion may significantly affect the load-bearing capacity, the capability to bend, and the deformation of a slab.

The loss of bond is much more critical than the loss of steel section (Mangat and Elgarf 1999). The degree of bond of corroded bars cannot be measured directly and the problem of identifying the properties of bond is far from being solved (Coronelli and Gambarova 2004).

The relationship between bond strength and corrosion must take into account the pressure due to the expansive action of corrosion, the tensile strength of cracked concrete, and the adhesion and friction between cracked concrete and corroded bars (Chung et al 2008).

In the model proposed by Bhargava et al (2007), bond strength of corroded bars increases while the concrete cover remains uncracked, usually up to corrosion level of $1-4 \%$ of mass loss in the rebar. However, bond is negligible at higher levels of corrosion.

A complete loss of bond and steel section at the lower reinforcement of the joists is assumed in this study as this facilitates the understanding of the worst possible scenario. 


\section{Residual capacity of a slab with corroded reinforcement}

Two collapse mechanisms govern the safety of damaged slabs, the bending in the center of the span and the shear near the supports. If initial tests indicate a possible shear failure, it is usually entirely underpin and reinforce the slab, given the danger of brittle fracture mechanism that produces. The most common cases of corrosion occur at the lower reinforcement, so that this investigation evaluates the residual safety in cases of failure mechanisms of flexural bending.

The members subjected to bending moment are particularly corrosion sensitive. In Spain, some $25.6 \%$ of slabs show signs of corrosion-induced damage (Vieitez and Ramirez 1984). The same source indicates that one-way slabs are the type of structure most affected by corrosion - representing $68 \%$ of all cases.

In some cases, even when all the lower reinforcement of any single joist was corroded, the slab did not reveal an unreasonable deflection or a high degree of cracking in partition walls or flooring. The structure appeared capable of withstanding considerable loads in those cases.

In case of severe corrosion, an expert must look after the rehabilitation works. There are no simulated evaluations or test for an entire building with corroded slabs in the literature, with its construction process, load history and phenomena of deterioration. Slabs affected by widespread corrosion until the ultimate load are simulated in this work. Two aspects that can help the experts to make decisions are analyzed.

On the one hand, there are acceptance criteria by a load test to determine if a building shall be permitted to remain in service for a specified time period. According to $\mathrm{ACl} 318$ (ACl 2008), a load test whose total load (including dead load already present) must not be less than $0.85(1.4 \mathrm{D}+1.7 \mathrm{~L})$ can be performed, where $\mathrm{D}$ is the 
sum of the dead loads and $L$ is the sum of the overloads. Measured deflections shall satisfy any of the following equations, where It is the joists span, and $\mathrm{h}$ is the slab thickness:

$$
\begin{aligned}
& \Delta_{1} \leq \frac{l_{t}^{2}}{20,000 h} \\
& \Delta_{r} \leq \frac{\Delta_{1}}{4}
\end{aligned}
$$

If the measured maximum and residual deflections, $\Delta 1$ and $\Delta r$, do not satisfy any of the above equations, it shall be permitted to repeat the load test.

On the other hand, the ultimate load in the simulations can be compared with the service load. The ratio between the ultimate load and the service load enables the estimation of the residual Load Factor (LF).

Vielma et al (2008) re-evaluate reliability factors for healthy R/C buildings in seismic analysis published by other authors. Table 1 shows Residual Safety index (RS) values. These values are obtained making a ratio between the real strength and the ideal strength, where the ideal strength is the strength with which the element is designed. The Load Factor and the Residual Safety index are equivalent.

Table 1 - Values for Residual Safety index

\begin{tabular}{ccc}
\hline Source & Type studied & Residual Safety index (RS) \\
\hline Osteraas and Krawlinker (1990) & Frames resistant to moments & $2.1-6.5$ \\
& Edge frames & $1.8-3.5$ \\
Hwang and Shinozuka (1994) & Frames with concentric diagonals & $2.2-2.8$ \\
Fischinger, Fajfar and Vidic (1994) & Concrete building with four levels & 2.2 \\
Mwafi and Elnashai (2002) & Low / medium height concrete build. & $1.6-4.6$ \\
& Concrete buildings of medium height with and & $2.0-3.0$ \\
\hline
\end{tabular}


The acceptance of a given Load Factor remains the responsibility of the expert. By analyzing the values of Table 1, it seems sensible assume 2 as a minimum acceptable value of reliability -LF in this work.

The criterion of the Load Factor can help decisions about the actions to take, but the meeting of the load test proposed by $\mathrm{ACl} 318(\mathrm{ACl} 2008)$ is essential to remain in use an existing structure.

\section{Building geometry}

To analyze a full slab with real boundary conditions, a theoretical three-storey apartment building, consisting of frames of flat beams, one-way slabs with R/C joists and masonry façades and inner walls, has been modeled. The axis-to-axis spans have usual values comprised between 4 and 5 meters (157.6 - 197.0 in).

The entire structure is modeled in space where each element is precisely dimensioned and located, and all the reinforcement is in its real position, as can be seen in Fig. 1.
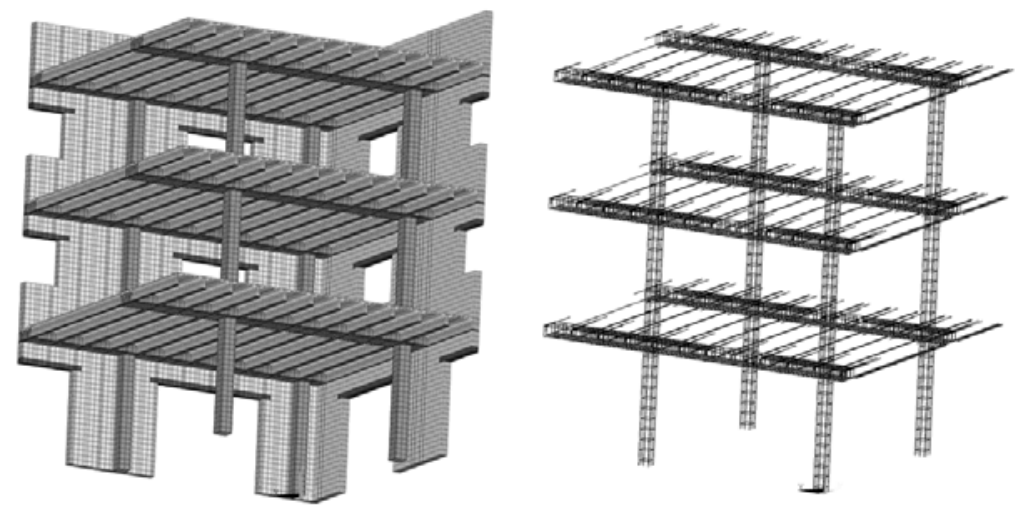

Fig. 1. Geometry of one quarter of the assessed building: (a) concrete and masonry, (b) steel reinforcement. 
The stability of the damaged structure is totally dependent on the degree of continuity and bracing of the entire structure. The assessment is realized on a middle floor with the appearance of the facade in the actual moment. Thus, the slab 2 has intermediate ideal boundary conditions.

There are many studies that exploit the symmetries of the models in finite element calculations (Hu et al 2003; Huang et al 2002; Mirmiran et al 2000; Schneider 1998; Shahawy et al 2000), and this approach reduces computing time. Because of this, a quarter of the building is modeled.

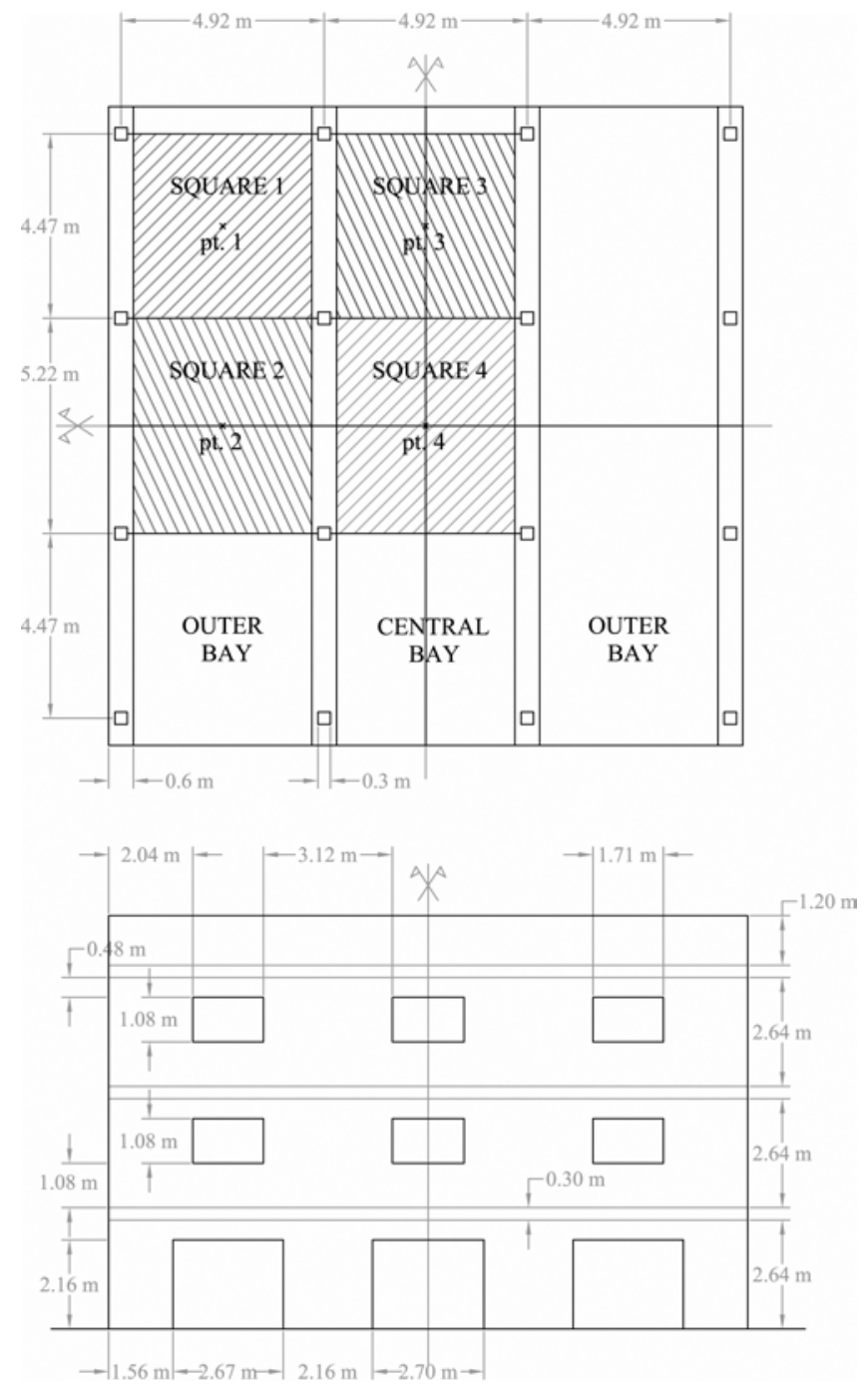

Fig. 2. Geometry of the assessed building. 
The geometric characteristics of the model are shown in Fig. 2 and 3:

- Inter-storey clearance: 2.64 m (104.02 in)

- Spans of beams to the column axes: $4.47-5.22-4.47$ m (176.12 - $205.67-$ 176.12 in)

- Spans of joists to the column axes: $4.92 \mathrm{~m}$ (193.85 in)

- $\quad$ Spacing between joists axes: $69 \mathrm{~cm}$ (27.19 in)

- Slab thickness: $0.30 \mathrm{~m}$ (11.82 in)

- $5 \mathrm{~cm}$ (1.97 in) top compression layer with Ø5 wire mesh with a spacing of 25 $\mathrm{cm}(9.85 \mathrm{in})$

- Joists: $9 \times 25$ with $2 \varnothing 10$ on the lower side and $2 \varnothing 10$ as negative reinforcement

- Beams: $60 \times 30,3 \varnothing 12+4 \varnothing 16$ as positive reinforcement, $3 \varnothing 12+4 \varnothing 20$ as negative reinforcement close to the columns, $4 \varnothing 6$ stirrups with variable separation at least every $12 \mathrm{~cm}$ (4.73 in)

- Columns: 30x30, 4Ø12, Ø6 stirrups each $24 \mathrm{~cm}$ (9.46 in)

- $\quad$ Bar cover: $3 \mathrm{~cm}$ (1.18 in)

a)

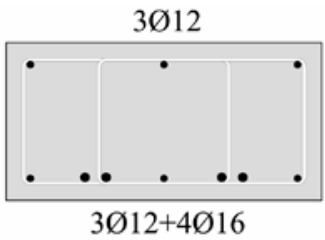

c)

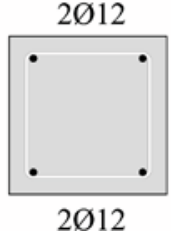

b)

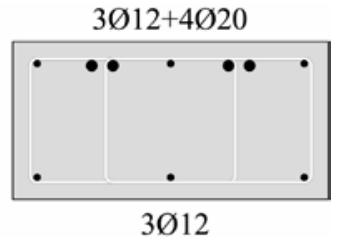

d)

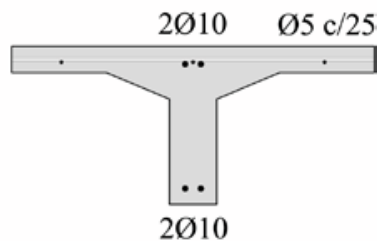

Fig. 3. Sections of the flat beams at the center of the span (a) and at the supports (b), sections of the columns (c), and section of the joists (d). 
The façade has conventional hollows on the ground and upper floors. Walls are modeled as solid $18 \mathrm{~cm}$-thick panels (7.09 in), as they consist of a cavity wall with an $11 \mathrm{~cm}$ (4.33 in) brick outer wall, an insulated air chamber, and a $7 \mathrm{~cm}$ (2.76 in) brick inner wall.

Loads and structural members have been applied in order of their real appearance during construction as follows:

- Load-bearing structure: concrete prismatic finite elements and links that represent the reinforcement in actual position.

- $\quad$ Dead load for reinforced concrete structure $\left(3,500 \mathrm{~N} / \mathrm{m}^{2}=0.51 \mathrm{psi}\right)$.

- Flooring load $\left(+1,000 \mathrm{~N} / \mathrm{m}^{2}=4,500 \mathrm{~N} / \mathrm{m}^{2}=0.65 \mathrm{psi}\right)$ : with $4,500 \mathrm{~N} / \mathrm{m}^{2}(0.65$ psi) are not yet built nor the partition walls nor the façade. The live load has not appeared. With this load, active deflection begins with respect to the partition walls.

- $\quad$ The façade is built at this moment. The façade weight will help loads to be withstood. This façade was modelled at the right moment to provide the stiffness necessary to prevent rotation and descent of structural elements.

- Weight of the partition walls $\left(+1,000 \mathrm{~N} / \mathrm{m}^{2}=5,500 \mathrm{~N} / \mathrm{m}^{2}=0.80 \mathrm{psi}\right)$ : the weight of these walls appears as pressure on the upper face of the slab.

- Quasi-permanent value of the live load $\left(+600 \mathrm{~N} / \mathrm{m}^{2}=6,100 \mathrm{~N} / \mathrm{m}^{2}=0.88 \mathrm{psi}\right)$. The value of the live load according to CTE (Ministerio de Vivienda 2006) and EC-1 (AENOR 1998) is $2,000 \mathrm{~N} / \mathrm{m}^{2}$ (0.29 psi); but to evaluate the residual Load Factor of the slab, the quasi-permanent value of the live load is first applied $\left(\psi_{2} \times\right.$ live load $\left.=0.3 \times 2,000 \mathrm{~N} / \mathrm{m}^{2}=600 \mathrm{~N} / \mathrm{m}^{2}=0.09 \mathrm{psi}\right)$. It is the value of the live load that is exceeded during $50 \%$ of the reference time (Ministerio de Vivienda 2006). The total value of all these loads means 6,100 
$\mathrm{N} / \mathrm{m}^{2}$ (0.88 psi), which is the minimum service load required in an accidental situation.

- $\quad$ Remaining live load $\left(+1,400 \mathrm{~N} / \mathrm{m}^{2}=7,500 \mathrm{~N} / \mathrm{m}^{2}=1.09 \mathrm{psi}\right)$.

- Load until collapse: the load continues increasing in the studied area until a collapse happens.

To evaluate the load-bearing capacity in cases where corrosion appears, the complete loss of bond and steel is simulated on lower reinforcement of the joists at the moment when the slabs are loaded to $6,100 \mathrm{~N} / \mathrm{m}^{2}(0.88 \mathrm{psi})$, the service load.

\section{Material properties}

Models of a complete R/C structure with façade include three materials: concrete, steel, and masonry. To model the behavior of these materials as realistically as possible, values of average strength rather than characteristic strength values (Ingeciber 2004) are used. Romao et al (2012) evaluate the Eurocode 8 Part 3 confidence factors for the characterization of concrete strength in existing structures.

\section{Concrete}

Multi-linear isotropic is the most widely used behavioral model for concrete. In Fig. 4 appears the stress-strain curve to represent this behavior for concrete provided by Bangash (1989).

The values of the concrete properties are obtained from Eurocode-2 (AENOR 1993) and the Spanish Code on Structural Concrete EHE-08 (Ministerio de Fomento 2008).

- Compressive strength: in studied models, an element is crushed when the compression exceeds the strength of the concrete. The failure criterion of William and Warnke (1975) is adopted. 


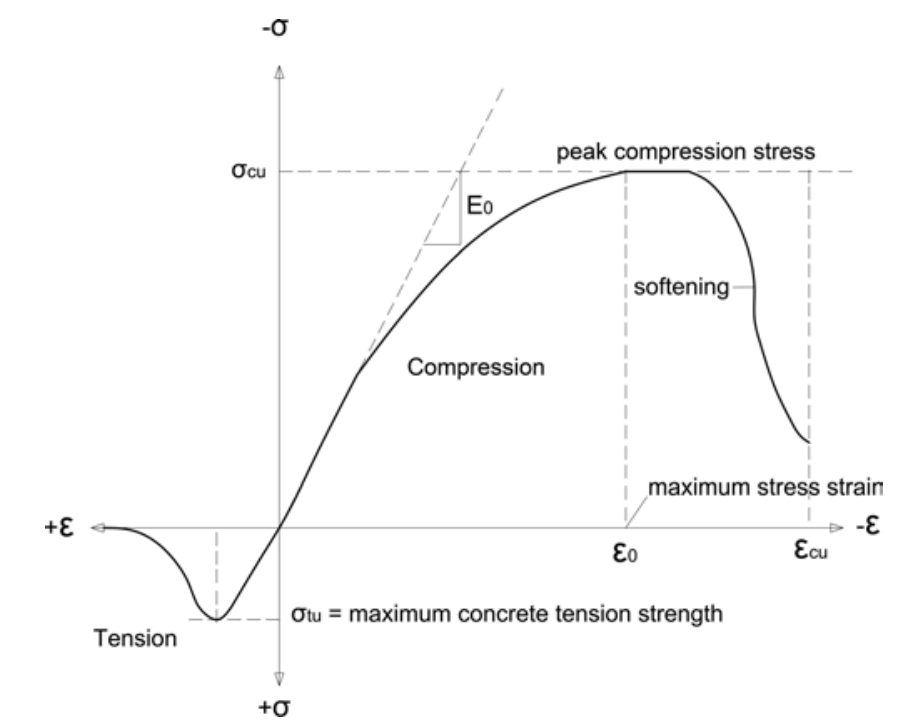

Fig. 4. Typical stress-strain curve of concrete subjected to uniaxial compression and tension.

- Tensile strength: concrete has a certain capacity for withstanding tensile forces. This strength is usually taken into account in FEM. As it is intended to evaluate the additional resistance mechanisms that appear actually, it is important to take this capability into account - even if the value is small. When concrete exceeds its tensile strength, cracking occurs and stiffness is then lost in a direction perpendicular to the crack.

- Shear transfer coefficients: Those coefficients valuate the shear portion transmitted from one side of the crack to the other. The coefficients for open cracks $\left(\beta_{t}\right)$ and closed cracks $\left(\beta_{c}\right)$ should be introduced in order to model concrete behavior. These coefficients may range from 0 , meaning a complete loss of transfer, to 1 , which corresponds to a very rough surface that transmits any force.

Shear failure is characterized by a very brittle behavior and often occurs suddenly. The shear transfer coefficients are very important for the simulations to take into account this kind of failure. A very hard work has been realized in order to calibrate these coefficients. Values within the minimum 
that produce an adequate convergence are searched in order to ensure that the results suitably reflect the mechanisms of shear.

According to Padmarajaiah and Ramaswamy (2002) values from 0.1 to 0.5 for open cracks, and from 0.7 to 0.9 for closed cracks can be used. Kachlakev et al (2001) attempted a number of comparative analytical studies to evaluate the influence of shear transfer coefficient. They used $\beta_{t}$ values within the range $0.05-0.25$ and encountered convergence problems at low loads with values less than 0.2 . In this study, conservative values of 0.15 and 0.6 are used respectively. These values make the simulations reflect the shear failure cases adequately.

In addition, it is necessary to validate these coefficients in cases where corrosion appears. Coronelli and Gambarova (2004) assess beam specimens with different degrees of corrosion. The Coronelli and Gambarova's specimens have been reproduced with the same shear transfer values used in this work (0.15 and 0.6), showing their actual behavior.

The developed work in this paper evaluates the residual safety level in R/C slabs with complete corrosion at the lower reinforcement of the joists. The chosen values of shear transfer coefficients reproduce the real behavior with severe corrosion at the reinforcement.

Table 2 shows all properties required to model concrete.

Steel

Steel has the same tensile and compressive behavior and a simplified isotropic bilinear behavior is assumed, which is extremely realistic. To define this behavior, elastic limit and tangent modulus values are needed. 
- $\quad$ The elastic limit for B-500-SD steel used in this study is $500 \mathrm{MPa}$ (72.5 ksi). Tensile tests for steel rebar have been conducted in an Ibertest STIB-200W machine and the results show that the elastic limit always exceeds $550 \mathrm{MPa}$ (79.75 ksi) and the ultimate strength exceeds $650 \mathrm{MPa}(94.25 \mathrm{ksi})$.

- $\quad$ The tangent modulus is the slope shown by the second branch of the stressstrain diagram. A value of $3 \mathrm{GPa}(435.0 \mathrm{ksi})$ is adopted, corresponding to $1.5 \%$ of the modulus of elasticity. With this value, problems of convergence are avoided and more realistic load-displacement diagrams are produced.

The remaining mechanical properties of steel have been taken from EC-2 (AENOR 1993) and EHE-08 (Ministerio de Fomento 2008) as depicted in Table 2.

Table 2 - Summary of material properties

\begin{tabular}{cccc}
\hline Properties & HA-30 Concrete & $\begin{array}{c}\text { B-500-SD } \\
\text { Steel }\end{array}$ & Ceramic Masonry \\
\hline$\rho\left(\mathrm{KN} / \mathrm{m}^{3}\right)$ & 25 & 78.5 & 14 \\
$\mathrm{f}_{\mathrm{cm}}(\mathrm{MPa})$ & 38 & - & 4 \\
$\mathrm{E}(\mathrm{GPa})$ & 28.6 & 200 & 2 \\
$\mathrm{f}_{\text {tm }}(\mathrm{MPa})$ & 3.39 & - & 0.2 \\
Poisson ratio $(\mathrm{v})$ & 0.20 & 0.30 & 0.20 \\
$\beta_{\mathrm{t}}$ & 0.15 & - & 0.15 \\
$\beta_{\mathrm{c}}$ & 0.6 & - & 0.6 \\
$\mathrm{f}_{\mathrm{y}}(\mathrm{MPa})$ & - & 500 & - \\
Tangent modulus $(\mathrm{GPa})$ & - & 3 & - \\
\hline Notes: $1 \mathrm{GPa}=1000 \mathrm{MPa}=145.0 \mathrm{ksi} ; 1 \mathrm{KN} / \mathrm{m}^{3}=.0 .003613 \mathrm{lb} / \mathrm{in}^{3}$
\end{tabular}

\section{Masonry}

The masonry is a complex and heterogeneous material. It can be micro modelled or macro modelled (Lourenço 2002). The first option is often used to study small simple elements, and bricks and mortar are often modelled separately, as well as the contact between both materials. However, macro modelling is employed in this study as large masonry structures are evaluated, where interaction between bricks and 
mortar is unimportant for understanding the overall performance. Furthermore, this study is focused on assessment of the reinforced joists.

- The value of masonry compressive strength is taken from the Basic Document for Structural Safety in Brick Buildings (DB SE-F) of the Spanish Technical Building Code (Ministerio de Vivienda 2006).

- $\quad$ The shear transfer coefficients employed in this study are based on a study by Cubel et al (2012).

Remaining data for simulating the behavior of the façade has been taken from studies by Brencich and de Felice (2009), and Dilrukshi et al (2010).

Table 2 shows the summary of the material properties values used in this research.

\section{Parameter verification}

Simulations cannot perfectly reproduce the reality, so it is very important to check the validity for the whole of this complex simulation.

In order to validate results and conclusions and confirm the accuracy of assumptions made in the studied cases, models and materials have been calibrated with research published by other authors.

Validation process starts with the analysis of healthy structures by comparing elements in terms of bending of the studies made by Barbosa and Ribeiro (1998), and Fanning (2001). In order to validate elements subjected to compression comparisons with Tavio and Tata (2009) studies are made.

In a second phase of the validation, flexural bending in corroded elements is evaluated. Tests made by Rodríguez et al (1997) -GEOCISA-Dragados Group-, 
which have been later simulated using Ansys by Coronelli and Gambarova (2004), have been assessed.

All beam specimens simulated by Coronelli and Gambarova have been reproduced according to their specifications successfully. For reasons of space, the results of all specimens are not included in this paper. The reinforcement section is reduced to simulate different degrees of corrosion and properties for concrete and steel are modified. In this paper only one healthy case (11.1) and one corroded case (11.4) are shown. In order to ascertain corrosion degree simulated in these specimens Table 3 is attached.

Table 3 - Corrosion attack at the reinforcement

\begin{tabular}{lcc}
\hline Beam no. & 11.1 & 11.4 \\
\hline Bottom bars & $2 \varnothing 10$ & $2 \varnothing 10$ \\
Bottom bars attack (mm) & - & 0.45 \\
Bottom bars corrosion & $0 \%$ & $17.2 \%$ \\
Top bars & $2 \varnothing 8$ & $2 \varnothing 8$ \\
Top bars attack (mm) & - & 0.52 \\
Top bars corrosion & $0 \%$ & $24.3 \%$ \\
Stirrups & $\varnothing 6 / 170$ & $\varnothing 6 / 170$ \\
Stirrups attack (mm) & - & 0.39 \\
Stirrups corrosion & $0 \%$ & $24.3 \%$ \\
\hline
\end{tabular}

Figure 5 and 6 show the correlation of results for samples 11.1 and 11.4 respectively.

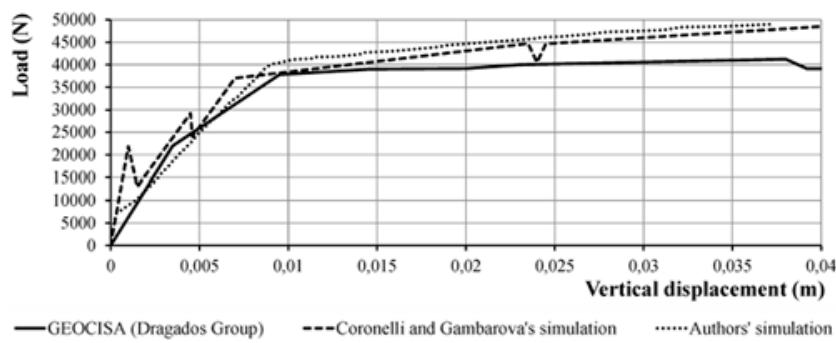

Fig. 5. Load-vertical displacement curves of specimen 11.1 in Rodríguez et al. tests (1997), in Coronelli and Gambarova's study (2004), and according to authors' model. 


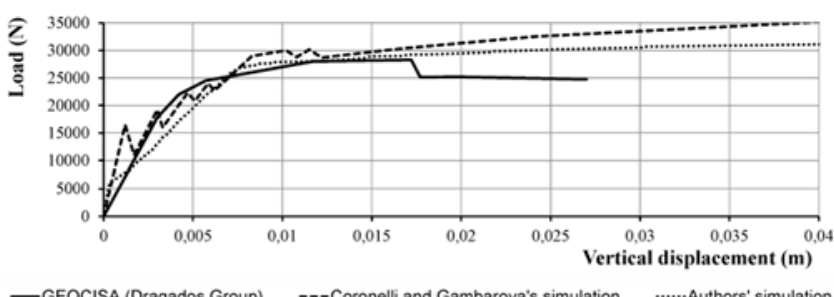

Fig. 6. Load-vertical displacement curves of specimen 11.4 in Rodríguez et al. tests (1997), in Coronelli and Gambarova's study (2004), and according to authors' model.

Calibration was carried out very thoroughly, as it is sometimes difficult to accept the large loads that structures with corroded reinforcements can support.

Coronelli and Gambarova's research simulates the corrosion effect with different percentages. In this paper the extreme case of overall corrosion is shown. With smaller degrees of reinforcement corrosion, the building is on the side of safety.

\section{Results of building specimens}

Calculations have considered all materials nonlinearity (concrete, steel, and brickwork), equilibrium in the deformed structure, and the loss of rigidity caused by the cracking and crushing of concrete. The reliability of an entire structure has been evaluated by applying nonlinear models (Val et al 1997), which are loaded to the ultimate load.

Stress in continuous slabs is distributed in a significantly different manner from distributions obtained using linear methods of calculation (Calavera 2003). When using plastic analysis reserves of strength that were not calculated in the design phase can be discovered, thus less reinforcement is needed (Micic et al 1995). 
Due to many factors involved in the safety it is appropriate to consider the overall response of the structure. It is obtained from the load-displacement relationships; as well as the effects produced by the incremental load (Vielma et al 2008).

Therefore load is applied incrementally to the entire building model, where the damaged slab has the real boundary conditions, obtaining load-vertical displacement curves at representative points of the slab. Comparisons are made between the healthy situation and the situations exhibiting a complete corrosion and bond loss in the lower reinforcement of one or more joists, with or without spalling, at different positions of the slab.

Table 4 - Load at admissible active deflection and Load Factor values for simulated cases

\begin{tabular}{|c|c|c|c|c|}
\hline \multicolumn{3}{|l|}{ Case } & \multirow{2}{*}{$\begin{array}{c}\begin{array}{c}\text { Load at admissible } \\
\text { active deflection } \\
\left(\mathrm{N} / \mathrm{m}^{2}\right)\end{array} \\
13,603\end{array}$} & \multirow{2}{*}{$\begin{array}{c}\begin{array}{c}\text { Load Factor } \\
\text { (LF) }\end{array} \\
Q_{\text {adm.act.def. }} / Q_{\text {serv. }} \\
2.23\end{array}$} \\
\hline $\mathrm{A}$ & & & & \\
\hline \multirow[t]{10}{*}{ B } & B.1. & & 14,335 & 2.35 \\
\hline & B.2. & & 9,150 & 1.50 \\
\hline & B.3. & B.3.1. & 13,481 & 2.21 \\
\hline & & B.3.2. & $-^{\mathrm{a}}$ & ${ }^{\mathrm{a}}$ \\
\hline & & B.3.3. & $-{ }^{\mathrm{a}}$ & $-{ }^{\mathrm{a}}$ \\
\hline & B. 4 . & B.4.1. & 12,261 & 2.01 \\
\hline & & B.4.2. & 11,981 & 1.96 \\
\hline & & B.4.3. & 11,464 & 1.88 \\
\hline & B.5. & & ${ }^{\mathrm{a}}$ & $-^{\mathrm{a}}$ \\
\hline & B.6. & & 12,952 & 2.12 \\
\hline \multirow[t]{10}{*}{$\mathrm{C}$} & C.1. & & 16,531 & 2.71 \\
\hline & С. 2 . & & 12,263 & 2.01 \\
\hline & С.3. & C.3.1. & 16,043 & 2.63 \\
\hline & & C.3.2. & ${ }^{\mathrm{a}}$ & $-{ }^{\mathrm{a}}$ \\
\hline & & C.3.3. & - & - \\
\hline & C. 4 . & C.4.1. & 14,579 & 2.39 \\
\hline & & C.4.2. & 14,516 & 2.38 \\
\hline & & C.4.3. & 14,037 & 2.30 \\
\hline & C. 5 . & & - & $-{ }^{a}$ \\
\hline & C.6. & & 15,345 & 2.52 \\
\hline
\end{tabular}


Table 4 shows results obtained with simulations of various models in original conditions and in cases of corrosion. In each case, the three slabs are loaded up to $6,100 \mathrm{~N} / \mathrm{m}^{2}$ (0.88 psi), and at this point certain joists are selected. These joists are corroded and load is added until the collapse to the zones affected by corrosion. The corroded joists are located in slab 2 in order to remain in an intermediate situation. Uncorroded bars models are also tested to establish the loads that can be endured.

Figure 2 shows the diagram of bays, squares and analyzed points of the theoretical building. Case A corresponds to a pristine conditions model where slab 2 is loaded until failure. Case B represents the specimens in which corrosion appears in the outer bay, which is modelled along its entire length in doubly symmetrical model. Several cases have been studied: B.1 (corrosion-free), B.2 (all joists corroded), B.3 (just three central joists in the square 1 are corroded), B.4 (just three central joists in the square 2 are corroded), B.5 (just one central joist in the square 1 is corroded) and B.6 (just one central joist in the square 2 is corroded). The cases with three corroded joists are simulated without spalling (B.3.1 and B.4.1), with central spalling (B.3.2 and B.4.2) and with total cover spalling (B.3.3 and B.4.3) to analyze the spalling influence. The cases with one corroded joist are simulated with total spalling (B.5 and B.6).

In case $\mathrm{C}$, corrosion is simulated in the central bay. Several models are studied in case $C$ analogously: the corrosion-free case (C.1); complete corrosion in this portion (C.2); corrosion in three central joists in the square 3 (C.3); corrosion in the three central joists of the square 4 (C.4); corrosion in the central joist of the square 3 (C.5); and corrosion in the central joist of the square 4 (C.6). The cases C.3.1 and C.4.1 are simulated without spalling. C.3.2 and C.4.2 models have central spalling, and 
C.3.3 and C.4.3 specimens have total cover spalling. Cases with one corroded joist are also simulated with total spalling (C.5 and C.6).

With the evaluation of these cases, the expert has an estimation of the remaining safety in cases of corrosion in some or in all the joists in the corner square, the square with joists continuity on one side, the square with beam continuity on one hand, and the square with beams and joists continuity in both directions.

These results are valid for the cases of usual spans. When analyzing a singular geometry, it is necessary to conduct a specific study.

The present paper proposes a methodology to assess the residual safety level in $\mathrm{R} / \mathrm{C}$ slabs damaged by severe joists corrosion. Based on simulations made with Ansys finite element software, the remaining capacity of a structure with pathology is evaluated in highly realistic models of an entire building, as the model shown in Fig. 7. The experts have two tools to help them in decision making. The essential tool is the $\mathrm{ACl} 318$ load test $(\mathrm{ACl} 2008)$ for existing structures. Buy in this paper other tool is proposed to assess the reliability, the Load Factor.

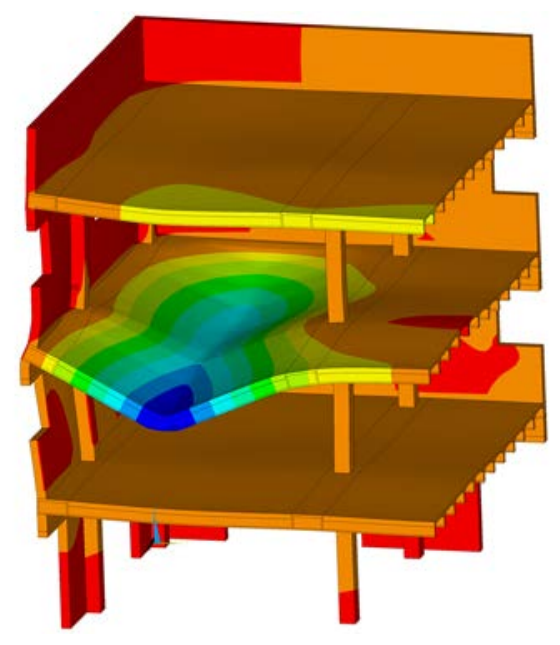

Fig. 7. Detail of collapse at ultimate load of corroded slab in a quarter of the building for case B.2. 
On the one hand, the Load Factor is obtained by making the ratio between the load that each model accepts for the permissible active deflection and the service load. The permissible active deflection is the maximum active deflection allowed for partition walls under the EHE code (Ministerio de Fomento 2008). Active deflection for partition walls is produced after these walls construction. As both the façade and the partition walls appear when the models are loaded to 4,500 N/m² (0.65 psi), according to the real constructive process, it is at this moment when the active deflection begins with respect to the partition walls. For this reason, the deflection at this load level is measured - which is equal to $1.9 \mathrm{~mm}(0.07 \mathrm{in})$. Given that the joist span between columns is $4.92 \mathrm{~m}$ (193.85 in), admissible active deflection is $1.23 \mathrm{~cm}$ (0.48 in) - equal to a value of $L / 400$, being $L$ the span value in meters, according to EHE code. By adding the deflection that there is at the moment of its construction, a vertical deformation of $1.42 \mathrm{~cm}(0.56 \mathrm{in})$ is reached. At this deformation value, load on each model should be measured. This load value is divided by $6,100 \mathrm{~N} / \mathrm{m}^{2}(0.88$ psi), which is the value of service load (value 1 of Load Factor), to obtain the Load Factor.

Due to model geometry, the points 2 and 4 are dominant in each bay with respect to the achieved vertical displacement, as the squares 1 and 3 have a smaller span. With the aim of maintaining the extension of the discussion, the results at the point 4 are only shown. But all the points have been studied, and the conclusions are drawn from the overall results of the research.

Figure 8 and 9 show the load-vertical displacement curves for point 4 . 


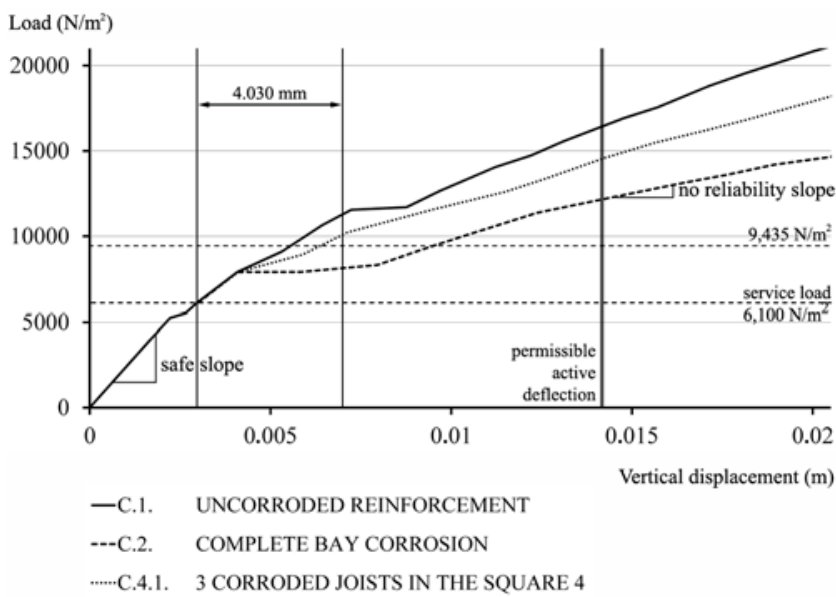

Fig. 8. Load-vertical displacement curves of specimens without spalling for point 4.

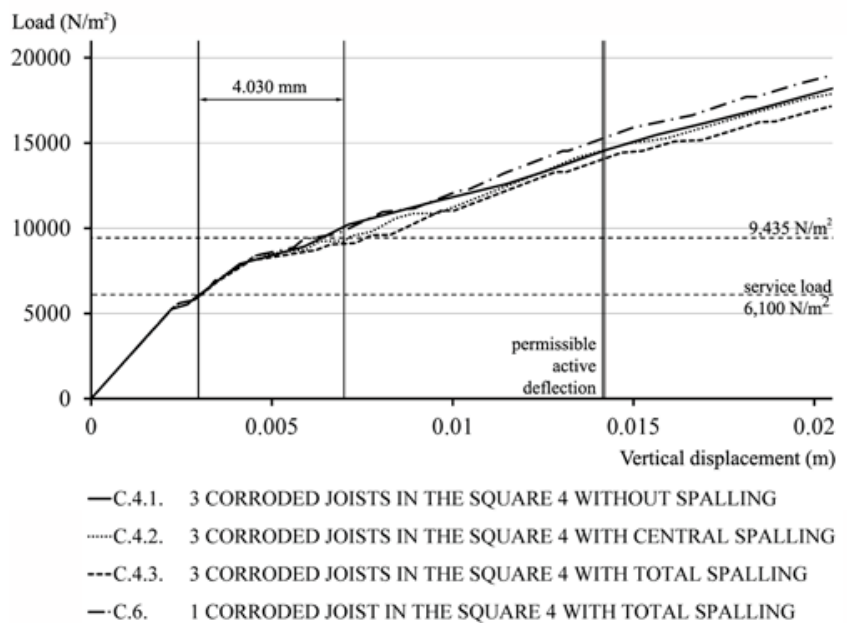

Fig. 9. Load-vertical displacement curves of specimens with 1 or 3 corroded joists for point 4 .

On the other hand, the way in which the standard $\mathrm{ACl} 318$ indicates whether a structure may continue in use is by conducting a load test. The slab analyzed area will be charged to a load value equal to $0.85(1.4 D+1.7 L)$, including dead load already present. The value of $D$ is the sum of the dead loads and the value of $L$ is the sum of the live loads.

In the present case, $D$ has a value of $5.500 \mathrm{~N} / \mathrm{m}^{2}(0.80 \mathrm{psi})$ and $L$ has a value of $2.000 \mathrm{~N} / \mathrm{m}^{2}$ (0.29 psi), according to CTE (Ministerio de Vivienda 2006), so that the total load value for the load test is equal to $9.435 \mathrm{~N} / \mathrm{m}^{2}$ (1.37 psi). According to $\mathrm{ACl}$ 318, if the deflection increase caused by the test does not exceed the value of $\Delta_{1}$, 
construction can continue in use. In the present case, with a span of $4.92 \mathrm{~m}$ (193.85 in) and a slab thickness of $0.30 \mathrm{~m}$ (11.82 in), the increased deformation limit is equal to $4.03 \mathrm{~mm}$ (0.16 in). When exceeding this limitation, retrieved deformation must be measured when slab is unloaded, and it should be bigger than $75 \%$ of $\Delta_{1}$. In this case, the construction state is also accepted to continue in use.

Figure 8 shows that corrosion-free case meets standard $\mathrm{ACl}-318$, and all joists in a bay corroded case does not meet this standard. The most interesting cases to evaluate at this point are those with just three central corroded joists in a square, the worst position.

The case C.4 is analyzed under three scenarios: no spalling (C.4.1), with overall spalling (C.4.3) and with partial spalling at the central zone of the joists (C.4.2). The specimen without spalling meets the $\mathrm{ACl} 318$ load test, as can be observed in Fig. 9, and has a Load Factor value of 2.38. In Fig. 10 can be seen that the specimens with spalling, total or partial, do not meet this load test, even with the simulation of the unload, since the unload remaining deflection is greater than the allowable. But these cases have still considerable load factor values, 2.29 and 2.37 respectively. Finally, a case with a single corroded joist at the center of the square has been assessed (C.6). This specimen meets $\mathrm{ACl} 318$ load test even with total spalling, and has a Load Factor value of 2.51 .

A collapse caused by shear failure of the slab is the most dangerous possible occurrence as the speed of the event may produce victims. The priority during a survey therefore is to guarantee that the reliability ratio is adequate for the shear solicitation at the joists ends, where the shear solicitation is maximal. 


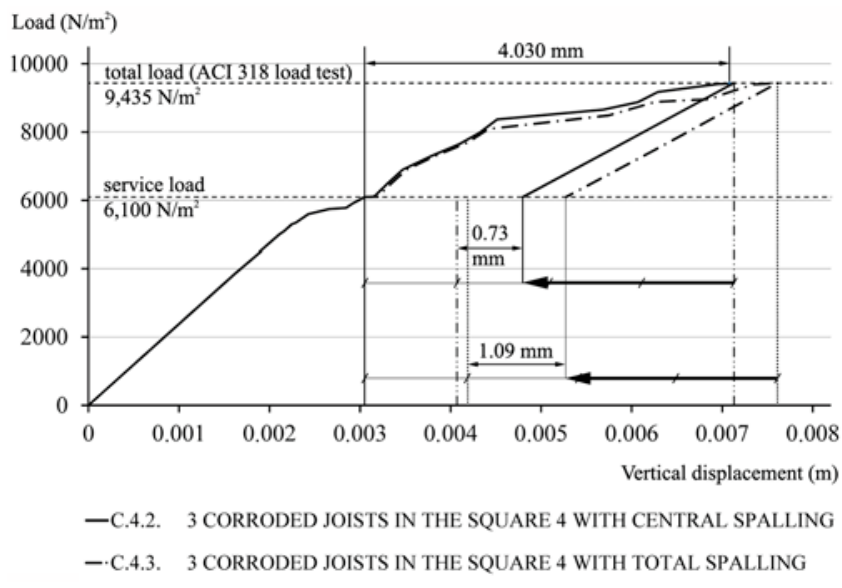

Fig. 10. Load-vertical displacement curves with unload according to $\mathrm{ACl}-318$ for point 4 in case C.4. with total and partial spalling.

In the studied cases, collapse will be caused by bending moment. Traditional spans of around five meters are used in this research work. With these spans, shear does not determine the ultimate load (assuming there is no deterioration in the concrete).

Furthermore, most of the cases of reinforcement corrosion are found on the lower side of the joists. In this study, the lower reinforcement of some joists is simulated completely corroded, leaving the top reinforcement at the joists ends perfect, uncorroded, as it usually happen. Therefore, in the area with the maximum shear stress there is steel reinforcement in perfect conditions. In this area, the flexural reinforcement is located in the upper side. In cases of real surveys, it has been proved that this upper reinforcement is tensioned, even in cases of total corrosion of the lower reinforcement. Shear is not the main stress. It implies that, except for the case of spalling of the concrete cover, the section is in a state of high reliability. In any event, a very conservative approach regarding the shear transfer coefficients for open and closed cracks has been used (Vercher 2013). With this conservative approach, simulations are able to represent the shear failure. 


\section{Summary and conclusions}

The methodology proposed in this research produces results consistent with the literature and with the many real cases observed in slabs with corrosion in the R/C joists with damage produced by bending.

The recommendations for the practical application of criteria for intervention in these cases of buildings with usual spans are:

- When total corrosion occurs only in one isolated joist, regardless of its degree and position, the structure meets $\mathrm{ACl} 318$ load test and presents appropriate Load Factor values. In these cases, the needed intervention is a complete protection and a light reinforcement.

- When severe corrosion appears in three adjacent joists at the center of a square, it is necessary to differentiate some cases. In this work, three assumptions are assessed: without spalling, with total spalling and with central spalling (Fig. 9).

In the case without spalling, the simulations meet $\mathrm{ACl} 318$ acceptance criterion only in cases with continuity at both ends.

However, the specimens do not meet $\mathrm{ACl} 318$ load test when spalling appears, total or in part. The tensile reinforcement has disappeared, and nonetheless the Load Factor has values of 2.29 and 2.37 respectively in the square 4 . In the square 2 the load factor values are lower: 1.88 and 1.96. This fact reassures the experts to perform the repair project, even light.

In humid zones, some of the joists (from 1 to 3 contiguous joists) will often have suffered corrosion of all the flexural reinforcement - yet the constructive 
elements remain undamaged and cracking is not excessive due to the deflection increase is very small.

The conclusion that can be drawn once the level of shear reliability is guaranteed is that when no more than three joists are corroded the repair is simple and there is no risk that the building will collapse. The required repair may even be as simple as fixing fiber bands to the lower side of the joists.

- Although less common, there are cases where corrosion has affected all the R/C joists of a bay. These cases require immediately shoring up the building and the general repair of the entire slab, which can range from the placement of lower joists to the fixing of fiber bands to the joists with a specific study of bond.

Regardless of the number of corroded joists in the area under study, much information about the residual safety can be acquired by estimating the slope in the position where the slab is within the load-displacement curve. This slope is obtained by a load test, and it is easy to identify if the structure is in the first or second stretch of behavior, because the slopes are very different, as can be seen in Fig. 8 .

It is especially recommended to reinforce the joists facing columns, as all simulations have shown that the failure occurs when the squares stop behaving independently, immediately after the failure of these joists. It can be easily seen in the break lines for an outer bay of a slab in Fig. 7. This recommendation can be generalized to the new buildings, where these joists can be designed with a more important lower reinforcement. It also produces more safety in case of fire or earthquake. 
An intervention is required in all cases of damaged joists, which can range from a protection to avoid future problems of durability to a comprehensive structural reinforcement.

\section{References}

American Concrete Institute (2008). "Building Code Requirements for Structural Concrete ( $\mathrm{ACl} 318-08)$ and Commentary. Strength Evaluation of Existing Structures." ACl, Michigan.

Asociación Española de Normalización (AENOR). (1993). “EUROCÓDIGO-2 (EC-2) Proyecto de estructuras de hormigón. Parte 1-1: Reglas Generales y Reglas para Edificación." Ed. AENOR, Madrid.

Asociación Española de Normalización (AENOR). (1998). "EUROCÓDIGO-1 (EC-1) Bases de proyecto y acciones en estructuras." Ed. AENOR, Madrid.

Bangash, M.Y.H. (1989). "Concrete and concrete structures: Numerical modelling and applications." Elsevier Applied Science, London and New York.

Barbosa, A.F., and Ribeiro, G.O. (1998). "Analysis of reinforced concrete structures using Ansys nonlinear concrete model." Comput. Mech., 1(8), 1-7.

Bhargava, K., Ghosh, A. K., Mori, Y., and Ramanujam, S. (2007). "Corrosioninduced bond strength degradation in reinforced concrete - Analytical and empirical models." Nucl. Eng. Des., 237, 1140-1157.

Brencich, A., and de Felice, G. (2009). "Brickwork under eccentric compression: Experimental results and macroscopic models." Constr. Build. Mater., 23(5), 19351946.

Calavera Ruiz, J. (2003). "Cálculo, construcción, patología y rehabilitación de forjados de edificación." Ediciones INTEMAC, Madrid. 
Chung, L., Najm, H., and Balaguru, P. (2008). "Flexural behavior of concrete slabs with corroded bars." Cem. Concr. Compos., 30, 184-193.

Coronelli, D., and Gambarova, P. (2004). "Structural assessment of corroded reinforced concrete beams: modelling guidelines." J. Struct. Eng., 130(8), 1214-1224. Cubel, F., Más, A., Vercher, J., and Gil, E. (2012). "Design and construction recommendations for brick enclosures with continuous air chamber." Constr. Build. Mater., 36, 151-164.

Dilrukshi, K.G.S., Dias, W.P.S., and Rajapakse, R.K.N.D. (2010). "Numerical modelling of cracks in masonry walls due to thermal movements in an overlying slab." Eng. Struct., 32, 1411-1422.

Fanning, P. (2001). "Nonlinear models of reinforced and post-tensioned concrete beams." Electron. J. Struct. Eng., 2, 111-9.

Foster, S.J., Bailey, C.G., Burgess, I.W., and Plank, R.J. (2004). "Experimental behaviour of concrete floor slabs at large displacements." Eng. Struct., 26, 12311247.

Hu, H. T., Huang, C. S., and Wu, M. H. (2003). "Nonlinear analysis of axially loaded concrete-filled tube columns with confinement effect." J. Struct. Eng.-ASCE, 129, 1322-1329.

Huang, C. S., Yeh, Y. K., Liu, G. Y., Hu, H. T., Tsai, K. C., Weng, Y. T., Wang, S. H., and Wu, M. H. (2002). "Axial load behaviour of stiffened concrete-filled steel columns." J. Struct. Eng.-ASCE, 128, 1222-1230.

Ingeciber, S.A. (2004). "Elemento Solid65. Recomendaciones de uso con ANSYS / CivilFEM." Ingeciber SA, Madrid.

Kachlakev, D., Miller, T., Yim, S., and Chansawat, K. (2001). "Finite Element Modeling of Reinforced Concrete Structures Strengthened with FRP Laminates." 
Civil and Environmental Engineering, Department California Polytechnic State University, San Luis Obispo.

Lourenço, P.B. (2002). "Computations on historic masonry structures." Prog. Struct. Eng. Mater., 4(3), 301-319.

Mangat, P., and Elgarf, M. (1999). "Flexural strength of concrete beams with corroding reinforcement." ACl Struct. J., 96, 149-158.

Micic, T.V., Chryssanthopoulos, M.K., and Baker, M.J. (1995). "Reliability analysis for highway bridge deck assessment." Struct. Saf., 17, 135-150.

Ministerio de Fomento (MF). (2008). "Instrucción de Hormigón Estructural (EHE-08)." Ed. Boletín Oficial del Estado, Madrid.

Ministerio de Vivienda (MV). (2006). "Código Técnico de la Edificación (CTE)." Ed. Boletín Oficial del Estado, Madrid.

Mirmiram, A., Zagers, K., and Yuan, W. (2000). "Nonlinear finite element modelling of concrete confined by fiber composites." Finite Elem. Anal. Des., 35, 79-96.

Padmarajaiah, S.K., and Ramaswamy, A. (2002). "A finite element assessment of flexural strength of prestressed concrete beams with fiber." Cem. Concr. Compos., $24,229-241$.

Reinforced Concrete Spanish Group (Grupo Español del Hormigón/GEHO). (1992). "Surveys on pathologies in concrete structures. GEHO Boletín 10." Ediciones GEHO-CEB, Madrid.

Rodriguez, J., Ortega, L.M., and Casal, J. (1997). "Load carrying capacity of concrete structures with corroded reinforcement." Constr. Build. Mater., 11(4), 239248. 
Romao, X., Gonçalves, R., Costa, A., and Delgado, R. (2012). "Evaluation of the EC8-3 confidence factors for the characterization of concrete strength in existing structures." Mater. Struct., online.

Schneider, S. P. (1998). "Axially loaded concrete-filled steel tubes." J. Struct. Eng.ASCE, 124, 1125-1138.

Shahawy, M., Mirmiram, A., and Beitelman, T. (2000). "Tests and modelling of carbon-wrapped concrete columns." Compos. Pt. B-Eng., 31, 471-480.

Tavio, T., and Tata, A. (2009). "Predicting nonlinear behaviour and stress-strain relationship of rectangular confined reinforced concrete columns with Ansys." Civ. Eng. Dimens., 11(1), 23-31.

Trocónis, O. (2006). "Durability of concrete structures: DURACON, an iberoamerican project. Preliminary results." Build. Environ., 41, 952-962.

Val, D., Bljuger, F., and Tankelevsky, D. (1997). "Reliability evaluation in nonlinear analysis of reinforced concrete structures." Struct. Saf., 19, 203-217.

Vercher, J. (2013). "Seguridad Residual en los Forjados con Corrosión Severa." PhD thesis, Universitat Politècnica de València, Valencia.

Vieitez, J. A., and Ramírez, J. L. (1984). "Patología de la Construcción en España: Aproximación Estadística. Resumen de Tesis Doctoral." Infor. Construc., 36, 5-15. Vielma, J.C., Barbat, A.H., and Oller, S.H. (2008). "Reserva de resistencia de edificios porticados de concreto armado diseñados conforme al ACl-318/IBC-2006." Ing., 18, 121-131.

Willam, K.J., and Warnke, E.D. (1975). "Constitutive model for the triaxial behaviour of concrete." Proc. Int. Assoc. Bridge Struct. Eng., ISMES, Bergamo, Italy, 19, 1-30. 